\section{耍 Heighten Science \\ P U B L I C I T I O N S Corporation ISSN 2573-6191}

\title{
Visualization and Evaluation of Changes after Rapid Maxillary Expansion
}

\author{
Ilija Christo Ivanov1*, Jan Dupej2, Sarka Bejdova², Veronika \\ Ciganova ${ }^{2}$, Dagmar Strakova ${ }^{1}$ and Tatjana Dostalova ${ }^{1}$ \\ ${ }^{1}$ Charles University, 2nd Medical Faculty, University Hospital in Motol, Department of \\ Stomatology; V Uvalu 84; 15006 Prague 5; Czech Republic \\ ${ }^{2}$ Charles University, 2nd Medical Faculty, Department of Anthropology and Human Genetics, \\ Faculty of Science; Vinicna 7; 12844 Prague 2; Czech Republic
}

\begin{abstract}
*Address for Correspondence: Ilija Christo Ivanov, Charles University, 2nd Medical Faculty, University Hospital in Motol, Department of Stomatology; V Uvalu 84; 15006 Prague 5; Czech Republic, Tel: +420 222516 248, Fax: +420 222 520 504; Email: ivanov@orthoprague.cz

Submitted: 09 March 2017

Approved: 28 March 2017

Published: 30 March 2017

Copyright: @ 2017 Ivanov IC, et al. This is an open access article distributed under the Creative Commons Attribution License, which permits unrestricted use, distribution, and reproduction in any medium, provided the original work is properly cited.
\end{abstract}

Keywords: Crossbite; Maxillary palate expansion; Haas expander; Charting

\section{ABSTRACT}

Objectives: The aim of the study was to develop a mathematical model for the visualization and evaluation of transversal palatal soft tissue changes; and to carry out a statistical evaluation of the changes in vertical and sagittal dimensions after rapid maxillary expansion treatment.

Material and Methods: 33 Caucasian children with posterior crossbite, 10 boys and 23 girls, aged 7 to 10 years (median 8 years 8 months) were treated with tooth-borne Haas type expander. Dental casts were digitalized by scanner and on the basis of quantitative mesh shape CPD-DCA analysis, coloured morphometrical maps were created. The statistical significance of individual vertex displacements was calculated by performing Hotelling's T2 paired test. To determine the significance of the vertical and sagittal profile changes, the paired t-test and Wilcoxon signed rank test were carried out in 20 patients

Results: Visualization of the palatal soft tissue widening showed it to be greatest in the areas of the second deciduous and first permanent molars with maximum of $0.75 \mathrm{~mm}$ for each palatal side. Hotelling's T2 paired test showed significant differences of $p<0.01$ in transversal width dimension. Cephalometric measurements of the changes to vertical and sagittal dimensions were statistically evaluated using the Wilcoxon and paired t-tests, and were shown to have insignificant values of $p>0.05$

Conclusion: The expansion appliance in children resolved the crossbite and led to palatal widening, which was clearly visualized by creating mathematical morphometric models. The cephalometric measurements carried out did not reveal statistically significant relevance in changes to facial vertical or sagittal dimensions.

\section{INTRODUCTION}

Posterior crossbite occurs in the deciduous and mixed dentition, with a prevalence varying from $4.6 \%$ to $23 \%$. It usually presents as unilateral and quite often leads to functional disorders [1-3]. The most frequently cited reasons for the development of crossbite are: jaw size and hereditary factors, delayed loss of deciduous teeth, mouth breathing, tongue thrusting, thumb sucking, and certain swallowing habits [4-6]. These factors may lead to conditions requiring orthodontic treatment since left untreated they can result in facial asymmetry, airway constriction and apnoea syndrome, TMJ disorders, and myofunctional muscle problems. The treatment of adult patients is very complex and often requires a combined orthodontic-surgical solution $[7,8]$.

Emerson Colon Angel (1822-1903) was the first to describe RME in 1860 in an article published in the San Francisco Medical Press. Haas in the 1960s proposed the fixed palatal acrylic expander for the rapid correction of transverse maxillary deficiency 
in children and adolescents $[9,10]$. Posterior crossbite and reduced dentoalveolar transverse widths in children can lead to a high risk of sleep-disordered breathing and nocturnal enuresis, thereby reducing quality of life. This can be an important reason for early crossbite treatment.

Rapid maxillary expansion (RME) is now routinely used to address transversal discrepancy in the development of the upper jaw, as the first stage of complex orthodontic treatment. Techniques for the evaluation of the effects of RME vary. They range from manual measurement of dental casts to cephalograms and moreover sophisticated digital probes with digital imaging systems, including 3D computed tomography [11].

\section{MATERIAL AND METHODS}

The observed group included 33 Caucasian children with posterior crossbite, 10 boys and 23 girls, aged 7 to 10 years (median age 8 years 8 months). The criteria for inclusion/exclusion to the group was posterior crossbite with a maxillary constriction more than $3 \mathrm{~mm}$ and patient under 10 years of age.

\section{Treatment phase}

Each patient was treated using a bonded acrylic tooth-borne Haas type expander (also called Hyrax), which consists of an acrylic base and a central screw. The position of the screw must be apical to the centre of resistance of the teeth, whilst avoiding traumatisation of the soft palate tissue. The appliance was attached to the teeth with self-cured orthodontic bonding adhesive (GC Fuji Ortho, Tokyo, Japan). Two measurements were taken to establish how much palatal widening was necessary to resolve the crossbite. In the upper jaw we measured the distance between the maxillary first molar mesiolingual lobes and in the lower jaw the distance between the central grooves of the lower mandibular first molars.

In the Hyrax screw used (hyrax®-17248, Dentaurum, Ispringen, Germany), one turn was equivalent to an expansion of $0.2 \mathrm{~mm}$. Patients were instructed to turn the screw twice a day, thus attaining a daily expansion of $0.4 \mathrm{~mm}$. Intraoral checks were performed once a week in order to observe the progress of palatal expansion until the completion of the active stage. In order to reduce the influence of relapse, an overexpansion by $25 \%$ was carried out.Before and after expander treatment, upper and lower jaw impressions were taken using alginate impression material to create plaster models.

\section{Digitalization}

Plaster casts of the maxilla were converted into digital models using the Roland LPX250 laser scanner with a lateral resolution of 200 microns (Roland DG, Hamamatsu, Japan). The laser scanner records the surface of an object placed on a rotating platform by means of a laser beam moving from the bottom to the top (software Dr. Picza 3). The maximum scan accuracy is $0.2 \mathrm{~mm}$, the maximum object height $40.64 \mathrm{~cm}$, the base diameter is $25.4 \mathrm{~cm}$ for rotary scan and up to $2.3 \mathrm{~cm}$ for square scan. Primary data were processed using Pixform reverse engineering software (Roland DG, Hamamatsu, Japan) and converted into digital images. In order not to vary the configuration of the model before and after treatment, 3.0 Morpho Studio software (Orad Hi Tec Systems Ltd., Kfar-Saba, Israel) was employed.

\section{Creation of mathematical models for visualization}

A dense mesh analysis was performed to allow for the detailed tracking of changes in palatal shape. This analysis was performed on triangular meshes obtained by the scanning of the palatal casts. For shape analysis, CPD-DCA (coherent point driftdense correspondent analysis) was employed, which has been successfully applied to 
the study of facial shape [12]. A total of five landmarks were placed on each mesh as shown in figure 1A. These landmarks are not used as shape descriptors and are not included in the statistical analysis. Their sole purpose is the rigid alignment of the studied surfaces. The alignment was performed using Generalized Procrustes Analysis (GPA). Thereafter a template, also known as base mesh, was chosen from the sample, one that had regular vertex coverage and appeared the least deformed. The choice of base mesh has no statistical bearing on the results as long as it is covered with vertices evenly enough. Vertex correspondences between the base and remaining meshes were calculated using the Coherent Point Drift (CPD) and closest-point-based approach [13]. Defective correspondences were detected using a triangle expansion criterion and removed. The result of this stage is a set of specimen descriptors comprising of quasilandmarks (former base mesh vertices) (Figure 1B and 1C). More importantly, because these quasilandmarks were formed by finding vertex correspondences, they were homologous and could be used for further statistical processing.

\section{STATISTICS}

The final stage consisted of calculating the Principal Component Analysis (PCA) of the quasilandmark coordinate matrix and visualization of the projected specimen descriptors in a scatter plot (Figure 2) [14]. Furthermore, paired analysis was performed. Specifically the quasilandmark coordinates resulting from CPD-DCA were organized into the arrays $X_{i, j, k}$ and $Y_{i, j, k}$ where $i$ the specimen index is, $j$ denotes the quasilandmark index, and $1 \leq k \leq 3$ denotes the coordinate dimension. Intuitively, $X$ holds the form before treatment and $Y$ after treatment. The mean vertex displacement, i.e. $d_{j}=\frac{1}{N} \sum_{i=1}^{N}\left\|X_{t, j}-Y_{t,}\right\|$ ( $N$ is the specimen count) was also calculated for each vertex and visualized as a map. Finally, the statistical significance of individual vertex displacement

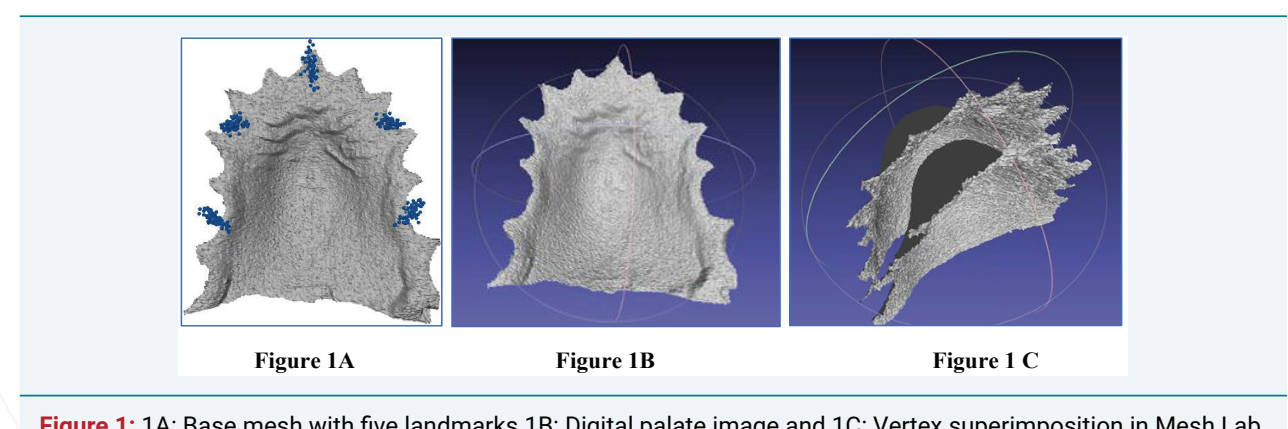

Figure 1: 1A: Base mesh with five landmarks 1B: Digital palate image and 1C: Vertex superimposition in Mesh Lab.

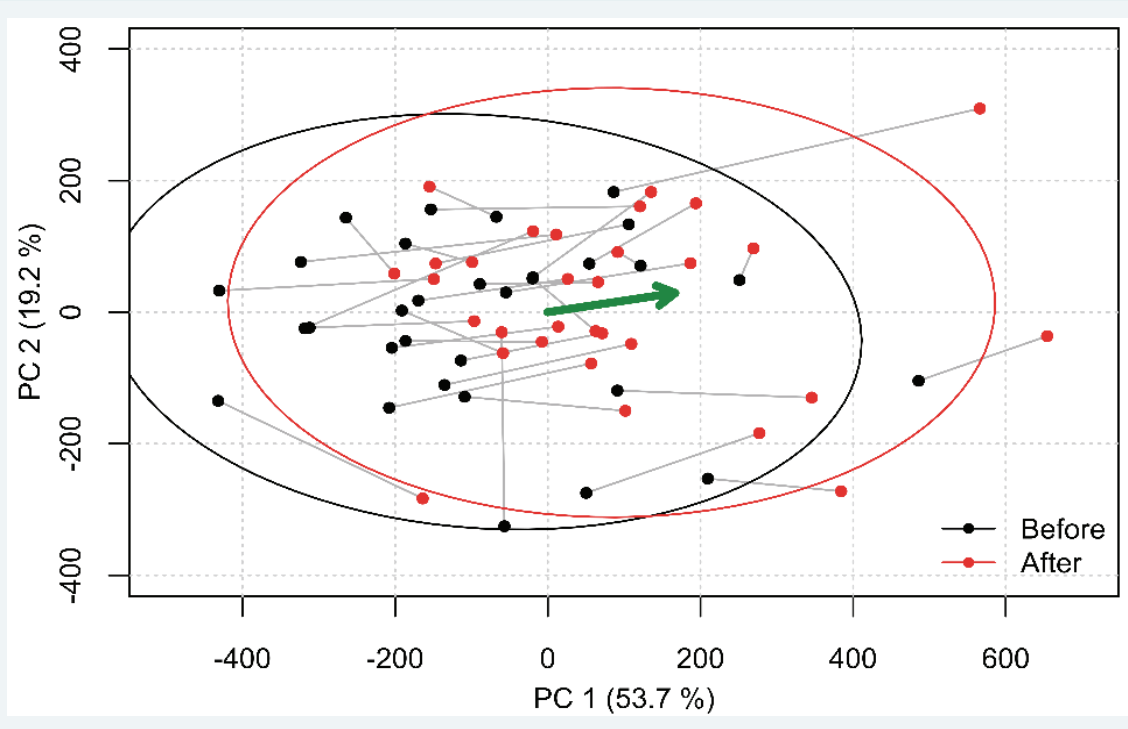

Figure 2: Scatter plot visualization of PCA analyses. 
was calculated by performing Hotelling's T2 paired test on the matrices $X_{j}$ and $Y_{j}$. The p-values for each vertex were also mapped onto the mean mesh, in order to visualize the areas of the palate where the displacement was statistically significant.

In order to evaluate the changes in vertical and sagittal planes, measurement of the profile X-rays before and after treatment was carried out in 20 patients. There were three groups of measurements covering a total of 10 parameters to specify changes in vertical and sagittal dimensions (Figure 3). The first group sought to assess changes in sagittal jaw relations and comprised of the SNA, SNB, ANB, and WITS values. The second focused on vertical alterations measuring the NSL-NL, NSL-ML and NL-ML planes and their angles. Thirdly, it was of interest to specify whether there were any changes to the angle between the upper and lower incisors (1+1-), the distance of the lower incisor from the A-Pg line, and the gonion angle These values were measured and compared on OPT before the insertion of the appliance and immediately after its removal. In order to rule out errors in the measurements the process was repeated a month later. Altogether, 80 profile X-ray measurements were completed. A paired $\mathrm{t}$-test and Wilcoxon test were performed to determine the significance of the changes. The R version 3.1.2 of Wilcoxon signed rank test was used [15].

\section{RESULTS}

To eliminate the maxillary jaw deficiency in our patients the palatal width between the mesiopalatal lobs of the upper first molars had to be increased by $3 \mathrm{~mm}$ to $10 \mathrm{~mm}$. The measurement was done at the plaster models. The mean expansion recorded within the group of 33 patients was $5.28 \mathrm{~mm}$. The results of the palatal soft tissue expansion were subjected to statistical analysis.

The results of the PCA are visualized in figure 2 as a scatter plot, showing the PC1 and PC2 scores of specimens before and after treatment. These two principal components explain over $73 \%$ of the sample variability. The points corresponding to a single specimen are connected with a line. Treatment-related changes appear to manifest themselves as an increase in the PC2 score. The green arrow represents the average change after treatment.

The paired analysis provides a colour map showing the average differences in the palatal form before and after treatment and their significance (Figure 4A and 4B). In figure $4 \mathrm{~A}$, blue indicates that treatment causes expansion, red means treatment-related retrusion near the incisors. In figure $4 \mathrm{~B}$, the statistical significance is visualized by mapping p-values to colours; bright blue and green indicates no statistical significance, while the deep shades of blue indicate that the local difference in the palatal form is significant. The darkest blue parts represent the maximum expansion in the area of the second deciduous and first permanent molars averaging $0.5-0.75 \mathrm{~mm}$ on each side. The plotting of the Hotelling's $\mathrm{T}^{2}$ paired test results also show the greatest areas of palatal expansion in dark blue, representing a high statistical significance of of a $\mathrm{p}<0.01$ (Figure 4C). The palatal depth showed to de decreased by average of a $0.5 \mathrm{~mm}$.

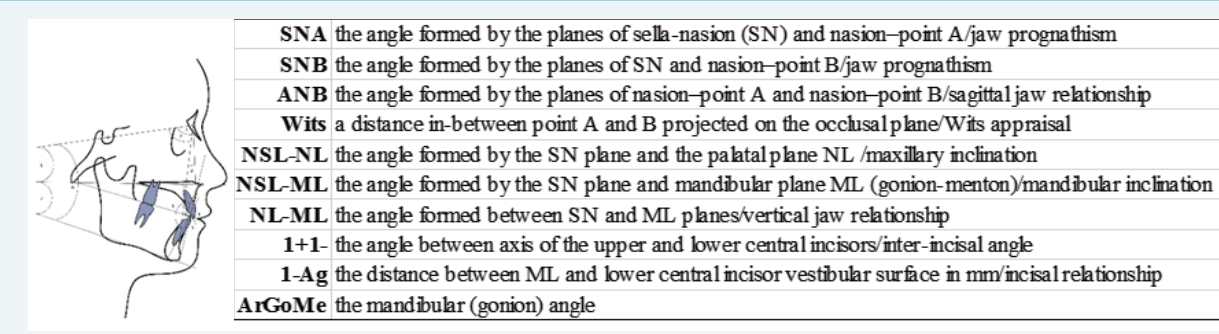

Figure 3: Definition of measurements on lateral cephalograms. 
The results of the statistical evaluation of cephalometric analysis are presented in table 1 and table 2 . The values monitored in relation to the profile X-rays showed the highest scores as follows: 1 ) the mean difference and standard deviation were highest in interincisal (1+1-: 1.31 to 5.98) and gonion (ArGoMe: -0.58 to 4.16 ) angles, followed by WITS (-0.79 to 2.94). 2) In the paired t-test, the highest p-values were for the angle between the Frankfurt plane and lower jaw (NSL/ML: 0.97) followed by the angle between the upper and lower jaw planes (NL/ML: 0.93). The Wilcoxon nonparametric test also showed the highest changes in these angles ( 0.77 and 0.88 respectively), followed by the gonion angle (0.85).

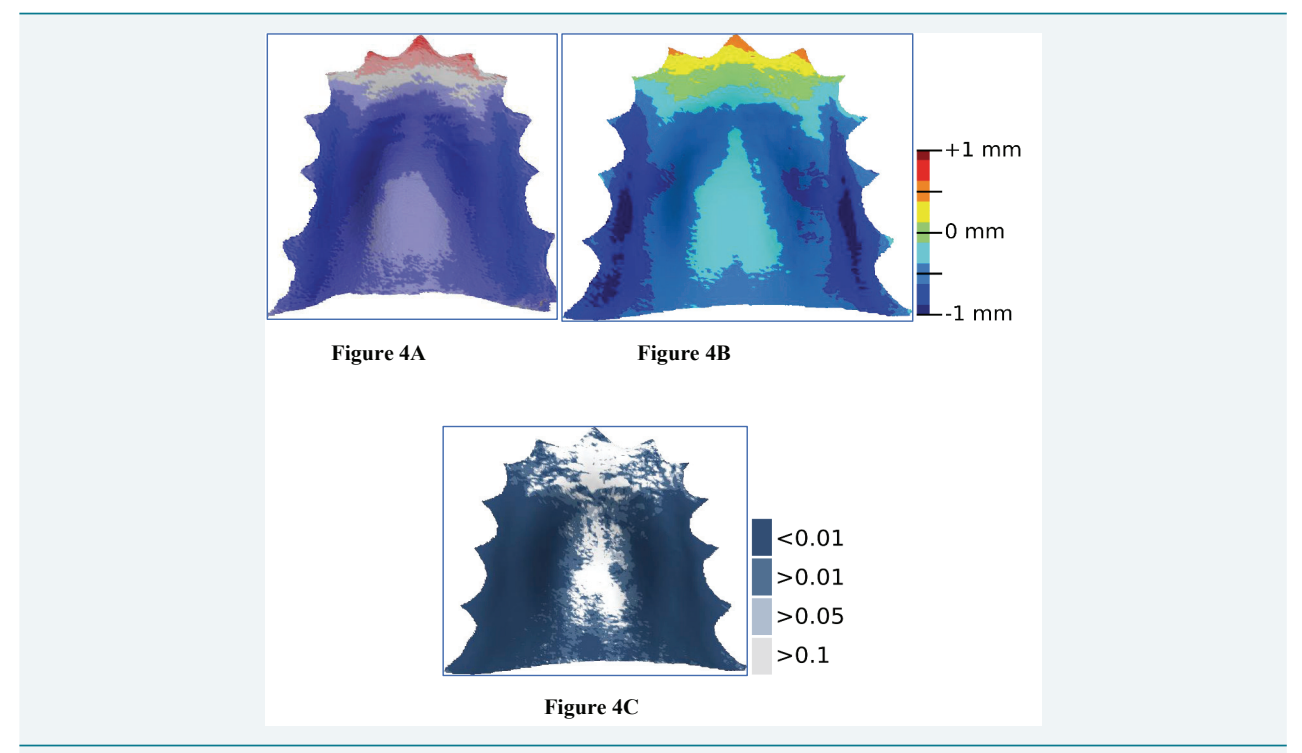

Figure 4: $\mathrm{A}$ and 4B: Colour map of average differences in the palate form before and after treatment with $1 \mathrm{~mm}$ scale; 4 C. Plotting of the Hotelling's T2 paired test with scale t-test.

Table 1: Cephalometric measurement evaluation by mean difference, standard deviation and $p$-values of paired t-test and Wilcoxon signed rank test.

\begin{tabular}{|c|c|c|c|c|}
\hline Parameter & mean diff. & SD & p paired & p Wilcoxon \\
\hline & \multicolumn{4}{|c|}{ Sagital changes } \\
\hline SNA & 0.000 & 2.484 & 1.000 & 0.911 \\
\hline SNB & -0.100 & 2.512 & 0.861 & 0.732 \\
\hline ANB & 0.135 & 1.820 & 0.744 & 0.538 \\
\hline Wits & -0.795 & 2.940 & 0.241 & 0.070 \\
\hline & \multicolumn{5}{|c|}{ Vertical changes } \\
\hline NSL/NL & 0.060 & 1.807 & 0.884 & 0.615 \\
\hline NSL/ML & 0.020 & 2.419 & 0.971 & 0.778 \\
\hline NL/ML & -0.050 & 2.807 & 0.937 & 0.881 \\
\hline & & Incisor position changes & \\
\hline $\mathbf{1 + 1 -}$ & 1.315 & 5.989 & 0.338 & 0.381 \\
\hline $\mathbf{1 - A p g}$ & 0.080 & 1.307 & 0.787 & 0.489 \\
\hline
\end{tabular}

Table 2: Mean error comparison before and after treatment.

\begin{tabular}{|c|l|c|c|}
\hline Nr & Parametr & Before & After \\
\hline $\mathbf{1}$ & SNA & 0.037 & 0.142 \\
\hline $\mathbf{2}$ & SNB & 0.125 & 0.142 \\
\hline $\mathbf{3}$ & ANB & 0.118 & 0.000 \\
\hline $\mathbf{4}$ & Wits & 0.138 & 0.147 \\
\hline $\mathbf{5}$ & NSL/NL & 0.110 & 0.008 \\
\hline $\mathbf{6}$ & NSL/ML & 0.335 & 0.288 \\
\hline $\mathbf{7}$ & NL/ML & 0.070 & 0.260 \\
\hline $\mathbf{8}$ & $1+1-$ & 0.355 & 0.157 \\
\hline $\mathbf{9}$ & 1-Apg & 0.018 & 0.047 \\
\hline
\end{tabular}


The lowest scores in the mean difference and standard deviation were seen for the SNA angle ( 0.00 to 2.48). The p-values from the paired t-test as well as the Wilcoxon test was the lowest in WITS appraisal ( 0.24 respectively 0.07 ).

However, neither the Wilcoxon, nor the paired t-test with $\mathrm{p}>0.05$ confirmed statistically significant changes for facial height or sagittal dimension alteration.

\section{DISCUSSION}

According to Haas, RME is an essential treatment option in the case of relative or absolute transverse maxillary deficiency, nasal stenosis, all types of Angle III Class, and in patients with cleft lip and palate, skeletal II Class 1 division malocclusion and some problems of dental arch length [16,17]. The method is contraindicated in patients with anterior open bite, large mandibular angle or convex face profile. The optimal age for expansion, in the study by Bishara et al., is between 13 and 15 years [18]. Treatment in adult patients often requires surgically assisted rapid palatal expansion, sometimes followed by surgical jaw asymmetry correction. Although it is possible to achieve expansion in older patients, the results are neither predictable nor stable.

Many studies have followed up on the RME results on both skeletal and dental levels. Methods employed ranged from the manual measurement of plaster models through the use of the symmetrograph (Lander and Muhl) to sophisticated digital imaging techniques (Bioscan OPTIMAS Imaging System, TriFoil Imaging, CA, USA) as used by Geran et al. [19] to measure models after RME in the early mixed dentition. Over the last decade, several 3D recording methods have become widely used in dentistry, including invasive (e.g. conebeam computed tomography) and non-invasive (e.g. laser scanning) procedures [20-26]. Invasive methods have been used to assess the skeletal effects of active maxillary expansion in three dimensions, whilst non-invasive 3D recording methods have been used to monitor subjects with a normal maxilla or a constricted maxilla, or to assess the treatment effects of maxillary expansion [10,23-26].

Our study looked for a mathematical model capable of creating a colour map to represent the results of maxillary expansion on soft tissues. The 3D scanning method used in our study allows for the scanning of one dental cast at a time. In the study by Australian authors Phatouros and Goonewardene [11], three-dimensional helicalcomputed tomography allowed for the simultaneous scanning of up to six dental casts. This represents a less time-consuming, but more expensive method than the one used by us. The mathematical method of coherent point drift-dense correspondent analysis was capable of creating the colour maps which clearly represents palatal expansion in our 33 patients. The use of Hotelling's $\mathrm{T}^{2}$ paired test confirmed the significance of the difference in the transversal width dimension changes achieved. This method gives us a sufficient visualization of the palatal enlargement. The sample treated by the above mentioned Australian authors [11] consisted of 43 children (mean age 9 years 1 month), treated with a bonded RME appliance. Their findings show significant increases in cross-sectional area observed across the permanent first molars $\left(15.3 \mathrm{~mm}^{2}\right)$. The colour map in our study similarly, showed maximum expansion in the area of the upper second deciduous and first permanent molars.

The Williams method was used for cephalometric profile measurements [27]. This method is sufficient to determine the skeletal and dental profile relationships and serve evaluation and diagnostic needs. When using the acrylic tooth-borne Haas type palatal expander we anticipated changes to the vertical and sagittal dimensions, due to the skeletal alteration and the thickness of the acrylic base, but these expectations were not borne out by our statistical evaluation.

The results of other studies differ. Reed et al. [28] evaluated both lateral cephalometric radiographs and orthodontic study casts in banded or bonded rapid 
palatal expansion groups. They found more vertical change in the banded, than in the bonded group. Because most of these changes were less than 1 degree, or $1 \mathrm{~mm}$ they may be considered clinically insignificant. On the other hand, in a study by Doruk et al. [29], downward and forward movement of the maxilla was observed in both RME and fan-type RME, treated by acrylic expanders. In their study, an acrylic-bonded fully tooth- and tissue-borne acrylic expander was used, whereas in our study, a toothborne acrylic expander was used.

The results of a study by Joseph Bouserhala et al. confirmed significant increases in sagittal maxillary transverse skeletal anterior and posterior direction. In their study CT images were taken [30]. Therefore further investigations by larger samples and CT methods are required to confirm or deny the significance of vertical and sagittal changes in treatment by acrylic tooth-borne Haas type expander.

\section{CONCLUSIONS}

The acrylic tooth-borne Haas type expander was successfully used for the treatment and correction of palatal deficiency in our patients.

Coherent point drift-dense correspondent analysis was applied and coloured palatal maps were generated which clearly showed the change in width of palatal soft tissues following RME. The method allowed us to measure and present correlation between intermolar widths, measured on the plaster models, to width changes on soft tissue palatal surface.

The cephalometric measurements carried out did not reveal statistically significant relevance in changes to facial vertical or sagittal dimensions. Further investigations by using more precise CT/CBCT methods should be required.

\section{ACKNOWLEDGEMENT}

This work was supported by IGA MZČR NT 13351-4 and 00064203 (FN Motol).

\section{REFERENCES}

1. Malandris M, Mahoney EK. Aetiology, diagnosis and treatment of posterior cross-bites in the primary dentition. Int J Paediatr Dent. 2004; 14: 155-166. Ref.: https://goo.gl/3aF55P

2. Ogaard B, Larsson E, Lindsten R. The effect of sucking habits, cohort, sex, intercanine arch widths, and breast or bottle feeding on posterior crossbite in Norwegian and Swedish 3-year-old children. Am J Orthod Dentofacial Orthop. 1994; 106: 161-166. Ref.: https://goo.gl/UzgJ9l

3. Ovsenik M. Incorrect orofacial functions until 5 years of age and their association with posterior crossbite. Am J Orthod Dentofacial Orthop. 2009; 136: 375-381. Ref.: https://goo.gl/ppPaCc

4. Bell WH, Epker BN. Surgical orthodontic expansion of the maxilla. Am J Orthod. 1976; 70: 517-528. Ref.: https://goo.gl/SWY6HG

5. Pogrel MA, Kaban LB, Vargerik K, Baumrind S. Surgically assisted rapid maxillary expansion in adults. Int J Adult Orthod Orthognath Surg. 1992; 7: 37-41. Ref.: https://goo.gl/YDMyMQ

6. Cozza P, Baccetti T, Franchi L, Mucedero M, Polimeni A. Sucking habits and facial hyperdivergency as risk factors for anterior open bite in the mixed dentition. Am J Orthod Dentofacial Orthop. 2005; 128: 517-519. Ref.: https://goo.gl/QVIxrH

7. Thilander B, Pena L, Infante C, Parada SS, de Mayorga C. Prevalence of malocclusion and orthodontic treatment need in children and adolescents in Bogota, Colombia. An epidemiological study related to different stages of dental development. Eur J Orthod. 2001; 23: 153-167. Ref.: https://goo.gl/allvbq

8. Croll TP, Riesenberger RE. Anterior crossbite correction in the primary dentition using fixed inclined planes. I. Technique and examples. Quintessence Int. 1987; 18: 847-853. Ref.: https://goo.gl/aksnkg

9. Haas AJ. The treatment of maxillary deficiency by opening the mid-palatal suture. Angle Orthod. 1965; 65: 200-217. Ref.: https://goo.gl/FctQq7

10. Haas AJ. Palatal expansion: just the beginning of dentofacial orthopedics. Am J Orthod. 1970; 57 219-255. Ref.: https://goo.gl/ZKf3SH 
11. Phatouros A, Goonewardene MS. Morphologic changes of the palate after rapid maxillary expansion: A 3-dimensional computed tomography evaluation. Am J Orthod Dentofacial Orthop. 2008; 134: 117124. Ref.: https://goo.gl/CVCvO0

12. Koudelová J, Dupej J, Brůžek J, Sedlak P, Velemínská J. Modelling of facial growth in Czech children based on longitudinal data: Age progression from 12 to 15 years using 3D surface models. Forensic Sci Int. 2015; 248: 33-40. Ref.: https://goo.gl/oszieq

13. Myronenko A, Song X. Point Set Registration: Coherent Point Drift. IEEE Trans on Pattern Anal Mach Intell. 2010; 32: 2262-2275. Ref.: https://goo.gl/Fmv51V

14. Core Team. R: a language and environment for statistical computing. R Foundation for Statistical Computing, Vienna, Austria. Ref.: https://goo.gl/AWSzwl

15. Abdi H, Williams LJ. Principal component analysis. WIREs Comp Stat. 2010; 2: 433-459. Ref.: https://goo.gl/wX66LQ

16. Timms DJ. The dawn of rapid maxillary expansion. The Angle Orthodontist. 1999; 69: 247-250. Ref.: https://goo.gl/y1HdGs

17. Haas AJ. Long-term posttreatment evaluation of rapid palatal expansion. Angle Orthod. 1980; 50 189-217. Ref.: https://goo.gl/hEJy08

18. Bishara SE, Staley RN. Maxillary expansion: Clinical implications, Am J Orthod Dentofacial Orthop. 1987; 91: 3-14. Ref.: https://goo.gl/eECT6B

19. Geran RG, McNamara JA, Baccetti T, Franchi L, Shapiro LM. A prospective long-term study on the effects of rapid maxillary expansion in the early mixed dentition. Am J Orthod Dentofacial Orthop. 2006; 129: 631-640. Ref.: https://goo.gl/cgGfPb

20. Garib DG, Henriques JF, Janson G, Freitas MR, Coelho RA. Rapid maxillary expansion--tooth tissueborne versus tooth-borne expanders: a computed tomography evaluation of dentoskeletal effects. Angle Orthod. 2005; 75: 548-557. Ref.: https://goo.gl/0oGQDS

21. Kartalian A, Gohl E, Adamian M, Enciso R. Cone-beam computerized tomography evaluation of the maxillary dentoskeletal complex after rapid palatal expansion. Am J Orthod Dentofacial Orthop. 2010; 138: 486-492. Ref.: https://goo.gl/KKSkal

22. Primozic J, Ovsenik M, Richmond S, Kau CH, Zhurov A. Early crossbite correction: a three-dimensional evaluation. Eur J Orthod. 2009; 31: 352-356. Ref.: https://goo.gl/Oxttrj

23. Ivanov Chi, Veleminska J, Dostalova T, Foltan R. Adolescent patient with bilateral crossbite treated with SARME: a case report evaluated by the 3D laser scanner and using FESA method. Prague Medical Report. 2011; 112: 305-315. Ref.: https://goo.gl/ACdVou

24. Gracco A, Malaguti A, Lombardo L, Mazzoli A, Raffaeli R. Palatal volume following rapid maxillary expansion in mixed dentition. Angle Orthod. 2009; 80: 153-159. Ref.: https://goo.gl/5Ve06v

25. Oliveira NL, Da Silveira AC, Kusnoto B, Viana G. Three-dimensional assessment of morphologic changes of the maxilla: a comparison of 2 kinds of palatal expanders. Am J Orthod Dentofacial Orthop. 2004; 126: 354-362. Ref.: https://goo.gl/OyMk8y

26. Primozic J, Perinetti G, Richmond S, Ovsenik M. Three-dimensional longitudinal evaluation of palatal vault changes in growing subjects. Angle Orthod. 2012; 82: 632-636. Ref.: https://goo.gl/BUXDfC

27. Williams S, Loster BW. Cephalometrics rationalised: Presenting the Kracovia Composite System (KCS). J Stoma. 2012; 65: 525-542. Ref.: https://goo.gl/70NQAQ

28. Reed N, Ghosh J, Nanda RS. Comparison of treatment outcomes with banded and bonded RPE appliances. Am J Orthod Dentofacial Orthop. 1999; 116: 31-40. Ref.: https://goo.gl/kfGB94

29. Doruk C, Bicakci AA, Basciftci FA, Agar U, Babacan H. A comparison of the effects of rapid maxillary expansion and fan-type rapid maxillary expansion on dentofacial structures. Angle Orthod. 2004; 74 : 184-194. Ref.: https://goo.gl/iOOUEw

30. Bouserhal J, Bassil-Nassif N, Tauk A, Will L, Limme M. Three-dimensional changes of the nasomaxillary complex following rapid maxillary expansion. Angle Orthod. 2014; 84: 88-95. Ref.: https://goo.gl/Q0zgX7 